\title{
Clinical and epidemiological aspects of cornea transplant patients of a reference hospital ${ }^{1}$
}

\author{
Giovanna Karinny Pereira Cruz ${ }^{2}$ \\ Isabelle Campos de Azevedo² \\ Diana Paula de Souza Rego Pinto Carvalho ${ }^{2}$ \\ Allyne Fortes Vitor ${ }^{3}$ \\ Viviane Euzébia Pereira Santos ${ }^{3}$ \\ Marcos Antonio Ferreira Júnior ${ }^{3}$
}

\begin{abstract}
Objective: clinically characterizing cornea transplant patients and their distribution according to indicated and post-operative conditions of cornea transplantation, as well as estimating the average waiting time. Method: a cross-sectional, descriptive and analytical study performed for all cornea transplants performed at a reference service $(n=258)$. Data were analyzed using Statistical Package for the Social Sciences, version 20.0. Results: the main indicator for cornea transplant was keratoconus. The mean waiting time for the transplant was approximately 5 months and 3 weeks for elective transplants and 9 days for urgent cases. An association between the type of corneal disorder with gender, age, previous surgery, eye classification, glaucoma and anterior graft failure were found. Conclusion: keratoconus was the main indicator for cornea transplant. Factors such as age, previous corneal graft failure (retransplantation), glaucoma, cases of surgeries prior to cornea transplant (especially cataract surgery) may be related to the onset corneal endothelium disorders.
\end{abstract}

Descriptors: Corneal Transplantation; Corneal Diseases; Health Profile.

\footnotetext{
Paper extracted from Master's Thesis "Corneal transplants in Rio Grande do Norte state: epidemiological and clinical aspects", presented to Universidade Federal do Rio Grande do Norte, Natal, RN, Brazil. Supported by Coordenação de Aperfeiçoamento de Pessoal de Nível Superior (CAPES), Brazil.

2 Doctoral student, Departamento de Enfermagem, Universidade Federal do Rio Grande do Norte, Natal, RN, Brazil. Scholarship holder at Coordenação de Aperfeiçoamento de Pessoal de Nível Superior (CAPES), Brazil.

${ }^{3}$ PhD, Professor, Departamento de Enfermagem, Universidade Federal do Rio Grande do Norte, Natal, RN, Brazil.
}

\section{How to cite this article}

Cruz GKP, Azevedo IC, Carvalho DPSRP, Vitor AF, Santos VEP, Ferreira Júnior MA. Clinical and epidemiological aspects of cornea transplant patients of a reference hospital. Rev. Latino-Am. Enfermagem. 2017;25:e2897. [Access Available in: . DOI: http://dx.doi.org/10.1590/1518-8345.1537.2897. 


\section{Introduction}

The cornea is a tissue in the human eye that has the purpose of improving the quality of the image formed in the retina. It is a convex, transparent, intensely innervated and sensitive membrane located in the anterior portion of the eyeball. It consists of the only avascular tissue in the human body(1-2).

Diseases that affect the cornea represent one of the leading causes of reversible blindness in the world. These diseases present diverse etiologies such as chronic, degenerative, inflammatory diseases, infectious diseases and trauma(3-5).

In cases where visual impairment caused by a corneal disease becomes severe, cornea transplant is indicated to restore visual function. It is considered the most frequent type of transplant in the world, and it has developed rapidly in recent years with the development of new surgical techniques(6-7).

Cases of eye diseases most commonly occur in developing countries, and most of these cases are preventable or treatable. Recent figures released by the World Health Organization (WHO) estimate the number of people with visual impairment at 285 million, and of these, 39 million people are diagnosed with blindness. Ninety percent of these visually impaired people live in low-income settings and $80 \%$ of them can be cured or could have their impairment avoided(8-10).

Epidemiological studies conducted with the objective of tracing the profile of patients awaiting cornea transplant as well as of transplanted patients in different demographic spaces, allows for comparing and analysing the variables that determine the most diverse outcomes involving cornea transplant.

Considering that the clinical profile of the patients who undergo cornea transplant varies according to the space, time and specific characteristics of the population due to several factors, the present study is based on the following questions: How is the distribution and clinical characterization of cornea transplant performed in a referral service in the state of Rio Grande do Norte? What factors related to the clinical characteristics of patients submitted to cornea transplant are inferred in the type of corneal disorder?

This study is justified by the need to determine how cornea transplants vary according to certain clinical characteristics that allow identifying groups at risk for prevention, in addition to generating hypotheses for later investigations.

In this context, we hope that these results may contribute toward improving organization and planning care for users who undergo cornea tissue transplant, in addition to promoting health professionals' training and to support discussion of the subject in seeking to offer specialized care in the pre- and postoperative periods based on attention to detecting and preventing complications.

This study aimed to clinically characterize transplanted patients and their distribution, describing the indicators for cornea transplantation, as well as estimating the average waiting time.

\section{Method}

This is an epidemiological study with a quantitative approach and a cross-sectional, descriptive and analytical design, carried out in the period from January to April 2015 at the Onofre Lopes University Hospital ( $H \cup O L)$ of the Federal University of Rio Grande do Norte (UFRN), a reference service for cornea transplantation in the state of Rio Grande do Norte.

Non-probabilistic sampling technique was employed since it involved all cornea transplant patients in the studied hospital between January 2010 and December 2014. This time interval was established due to the initiation of cornea transplants occurring from 2010 until the end of the year preceding data collection. Thus, a total of 258 cornea transplant procedures were performed in 241 patients, who met the following eligibility criteria: individuals of all ages and both genders; attended by this hospital within the studied period, regardless of the indicated clinical condition for the procedure. Those who presented incomplete, ineligible or missing/lost medical records were excluded.

Data collection was conducted from the records of the surgical information sheets of cornea transplants found in the Ocular Tissue Bank of the state of Rio Grande do Norte and from the respective patient records for patients submitted to the procedure at the HUOL. The records were subsequently analyzed using a structured script, specifically developed to systematize data collection for this study in order to meet the proposed objectives.

The structured script was intended for investigating clinical information variables. This instrument contains closed questions and was filled out by the researcher using data available from secondary sources.

The analyzed variables were: gender, age, race, operated eye, surgical purpose, ocular diagnosis, area of residence, mesoregion, waiting time, type of corneal disorder, type of surgery, type of keratoplasty, previous surgery, previous graft failure, vascularization, eye 
classification, glaucoma, in combination with cataract extraction and transoperative complications.

Data were processed and analyzed using the Statistical Package for Social Sciences (SPSS) version 20.0 and presented in tables. Descriptive statistics were used for univariate analysis using absolute and relative frequencies, means and medians. The chisquare test $\left(X^{2}\right)$ was used with a 0.05 significance level for inferential analysis between the variable "type of corneal disorder" with the variables gender, age, race, previous surgery, previous graft failure, vascularization, eye classification, glaucoma and transoperative complications.

The research protocol was approved by the Research Ethics Committee of the Federal University of Rio Grande do Norte regarding its ethical and methodological aspects, and in accordance with resolution CNS no. 466/2012 under opinion 876.177 and CAAE number 37533014.8.0000.5537.

\section{Results}

\section{Distribution and clinical characterization}

Of the 258 cornea transplants studied, $51.16 \%$ were performed on male patients, $58.14 \%$ on pardo/ brown, $37.21 \%$ on white and $4.55 \%$ on black individuals. In relation to age, the following frequencies were found for age group intervals: up to 20 years $(10.85 \%), 21$ to 30 years $(18.22 \%), 31$ to 40 years $(9.30 \%), 41$ to 50 years $(10.47 \%), 51$ to 60 years $(14.73 \%)$ and over 60 years $(36.43 \%)$. The mean age of the patients was 49.33 years, with a standard deviation of 22.60 , while half of the patients were aged up to 52.50 years.

Figure 1 shows the geographic distribution of cornea transplants by condition and mesoregion in the state of Rio Grande do Norte. Of the total of 258 cornea transplants, 249 occurred in patients residing in the state of Rio Grande do Norte, and nine transplants were performed in patients residing in other states. After analyzing the cases by place of residence of the patient, it was observed that $87.60 \%$ of them lived in the urban zone and $57.75 \%$ came from the Eastern Potiguar mesoregion, with the highest concentration of cases in the city of Natal $(37.98 \%)$, which is the state capital.

Regarding temporal distribution, $44.18 \%$ of the patients underwent their transplant in 2014, while the years 2010, 2011, 2012 and 2013, obtained 3.49\%, $17.83 \%, 21.32 \%$ and $13.18 \%$, respectively.

The ocular diagnoses found were: keratoconus (26.36\%), interstitial keratitis $(22.48 \%)$, bullous keratopathy $(20.93 \%)$, leukoma $(9.3 \%)$, late failure $(9.3 \%)$, Fuchs's dystrophy $(5.03 \%)$, other corneal dystrophies $(2.33 \%)$, corneal degeneration (1.55\%), perforation $(1.16 \%)$, primary failure $(0.78 \%)$, ocular burn $(0.39 \%)$ and endothelial failure after trauma $(0.39 \%)$.

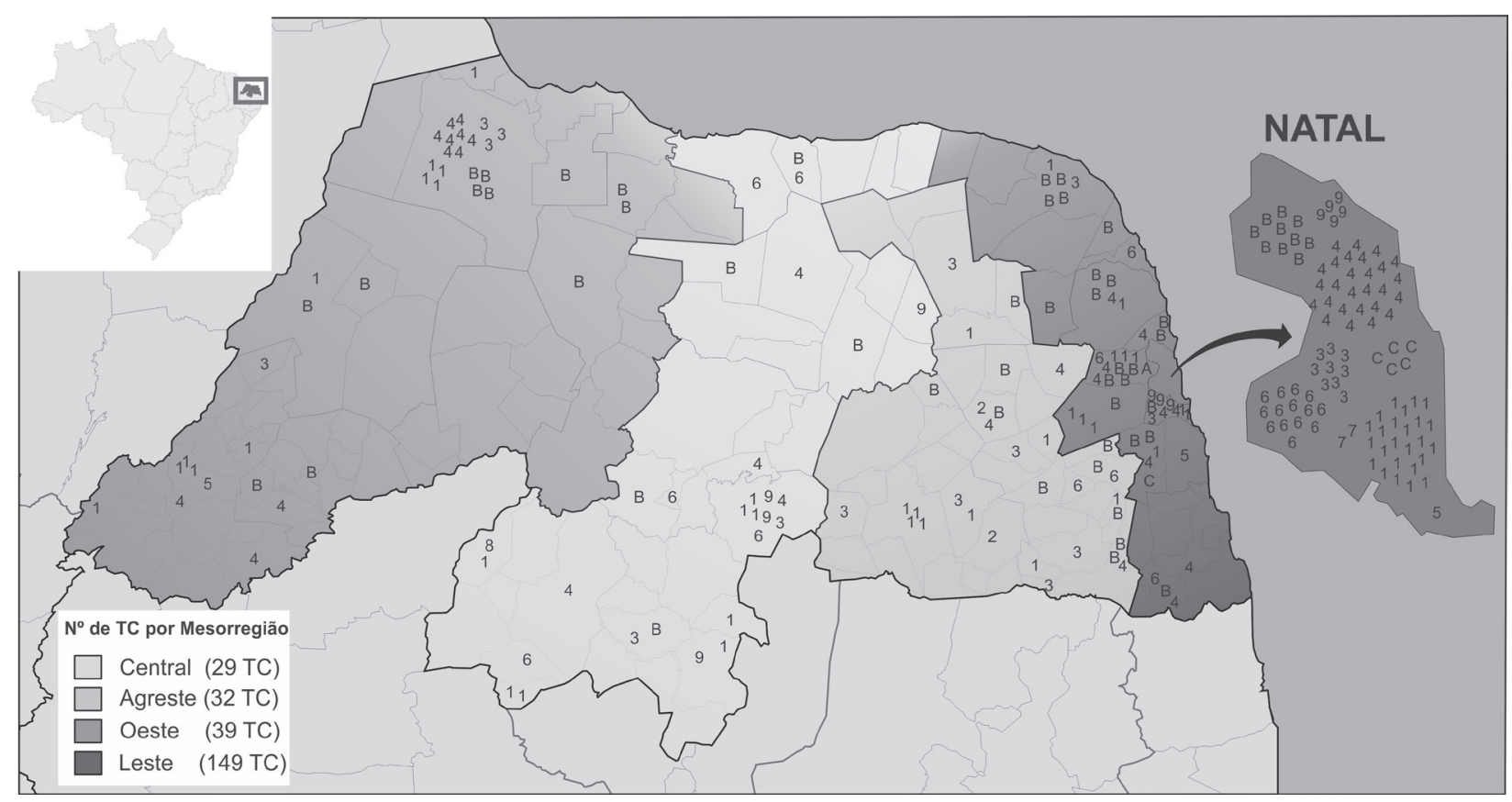

1 Keratoconus 2 Perforation, 3 Leukoma, 4 Bullous keratopathy, 5 Corneal Degeneration, 6 Late Failure, 7 Primary failure, 8 Endothelial failure, 9 Fuchs's dystrophy, A Ocular Burn, B Interstitial Keratitis, C Other Dystrophies.

Figure 1 - Geographic distribution of cornea transplants performed by condition and mesoregion in RN - Natal, RN, Brazil, 2015. 
Regarding the type of disorder classified according to the affected cornea layer, $62.02 \%$ were stromal, $36.43 \%$ were endothelial and $1.55 \%$ were classified as "others" since they were cases in which more than one layer of the cornea was involved (three cases of perforations and one case of burn). No cases of epithelial disturbance were observed.

The overall average waiting time for undergoing cornea transplant from the time of enrollment in the National Transplant System until the procedure was performed was 127.19 days, while half of the patients waited for up to 136 days (CV: $85.39 \%$ ). The waiting time in days for elective or emergency surgeries was 172.63 and 9.03, respectively.

Table 1 shows the clinical and surgical profile of the 258 cornea transplant procedures performed at the HUOL during the study period.

Table 1 - Clinical and surgical profile of patients who underwent cornea transplant $(n=258)$. Natal, RN, Brazil, 2015.

\begin{tabular}{|c|c|c|}
\hline Characteristics & $\mathbf{N}$ & $\%$ \\
\hline \multicolumn{3}{|c|}{ Previous graft failure } \\
\hline No & 231 & 89.53 \\
\hline Yes & 27 & 10.47 \\
\hline \multicolumn{3}{|l|}{ Operated eye ${ }^{*}$} \\
\hline Right & 129 & 50.19 \\
\hline Left & 128 & 49.81 \\
\hline \multicolumn{3}{|l|}{ Eye classification* } \\
\hline Phakic & 188 & 76.42 \\
\hline Pseudophakic & 52 & 21.14 \\
\hline Aphakic & 06 & 2.44 \\
\hline \multicolumn{3}{|l|}{ Vascularization* } \\
\hline No & 142 & 57.96 \\
\hline Yes & 103 & 42.04 \\
\hline \multicolumn{3}{|l|}{ Glaucoma* } \\
\hline No & 219 & 89.39 \\
\hline Yes & 26 & 10.61 \\
\hline \multicolumn{3}{|l|}{ Previous surgery* } \\
\hline No & 150 & 60.0 \\
\hline Yes & 100 & 40.0 \\
\hline \multicolumn{3}{|c|}{ Reason for transplant * } \\
\hline Optical & 194 & 75.49 \\
\hline Tectonic & 45 & 17.51 \\
\hline Therapeutic & 18 & 7.0 \\
\hline \multicolumn{3}{|l|}{ Surgical urgency } \\
\hline Elective & 184 & 71.32 \\
\hline
\end{tabular}

(continue...)
Table 1 - (continuation)

\begin{tabular}{lcc}
\hline Characteristics & N & $\%$ \\
\hline Urgent & 74 & 28.68 \\
Type of keratoplasty* & & \\
$\quad$ Penetrating & 228 & 92.68 \\
Lamellar & 18 & 7.32 \\
Keratoplasty combined with cataract extraction* & & \\
No & 227 & 92.65 \\
Yes & 18 & 7.35 \\
Intraoperative complication* & & \\
No & 219 & 90.87 \\
Yes & 22 & 9.13 \\
\hline
\end{tabular}

*Missing data

From the total of performed cornea transplants, $50.19 \%$ were on the left eye, and $75.49 \%$ for an optical reason classified as phakic (76.42\%), pseudophakic (21.14\%) and aphakic (2.44\%). Vascularization of the recipient's corneal tissue and glaucoma were present in $42.04 \%$ and $10.61 \%$ of the cases, respectively.

Penetrating keratoplasty was the surgical technique used in $92.68 \%$ of the transplants. Cases of previous surgeries on the eye submitted to cornea transplant were observed in $40 \%$ of the patients, and $10.47 \%$ were submitted to retransplantation due to previous graft failure.

\section{Relationship between type of corneal disorder and clinical characteristics}

The variable "type of corneal disorder" was isolated for calculating the probability of association corresponding to the classification of the affected cornea layer, which can be classified as epithelial, stromal or endothelial. An inferential analysis was established with the clinical variables gender, age, race, previous surgery, previous graft failure, vascularization, eye classification, glaucoma, and transoperative complications, as shown in Table 2.

The chi-square test $\left(X^{2}\right)$ (with a significance level of 0.05 ) found evidence of statistical difference between the "type of corneal disorder" variable with gender, age, previous surgery, previous graft failure, eye classification and glaucoma. A relationship was found between stromal disorder, males, and patients aged 20 to 50 years. Endothelial disorder was associated with age greater than 60 years, previous surgery, previous graft failure, eye classification as pseudophakic and aphakic, and the presence of glaucoma. 
Table 2 - Type of corneal disorder versus clinical characteristics of patients undergoing cornea transplant $(n=258)$. Natal, RN, Brazil, 2015.

\begin{tabular}{|c|c|c|c|c|c|}
\hline \multirow[b]{2}{*}{ Characteristics } & \multicolumn{3}{|c|}{ Type of corneal disorder } & \multirow{2}{*}{$\begin{array}{l}\text { Total } \\
\%(n)\end{array}$} & \multirow[b]{2}{*}{$p^{*}$} \\
\hline & $\begin{array}{c}\text { Stromal } \\
\%(n)\end{array}$ & $\begin{array}{c}\text { Endothelial } \\
\%(n)\end{array}$ & $\begin{array}{c}\text { Others } \\
\%(n)\end{array}$ & & \\
\hline \multicolumn{6}{|l|}{ Gender } \\
\hline Male & $73.48(97)$ & $23.48(31)$ & $3.04(4)$ & $100(132)$ & 0.000 \\
\hline Female & $50.0(63)$ & $50.0(63)$ & & $100(126)$ & \\
\hline \multicolumn{6}{|l|}{ Age groups (in years) } \\
\hline Up to 20 & $96.43(27)$ & - & $3.57(1)$ & $100(28)$ & 0.000 \\
\hline $21-30$ & $87.23(41)$ & $10.64(05)$ & $2.13(1)$ & $100(47)$ & \\
\hline $31-40$ & $95.83(23)$ & $4.17(01)$ & - & $100(24)$ & \\
\hline $41-50$ & $77.78(21)$ & $18.52(05)$ & $3.7(1)$ & $100(27)$ & \\
\hline $51-60$ & $52.63(20)$ & $47.37(18)$ & - & $100(38)$ & \\
\hline Over 60 years & $29.79(28)$ & $69.15(65)$ & $1.06(1)$ & $100(94)$ & \\
\hline \multicolumn{6}{|l|}{ Race } \\
\hline Pardo/Brown & $62.0(93)$ & $35.33(53)$ & $2.67(4)$ & $100(150)$ & 0.086 \\
\hline White & $58.33(56)$ & $41.67(40)$ & - & $100(96)$ & \\
\hline Black & $91.67(11)$ & $8.33(01)$ & - & $100(12)$ & \\
\hline \multicolumn{6}{|l|}{ Previous surgery } \\
\hline Yes & $27.0(27)$ & $73.0(73)$ & - & $100(100)$ & 0.000 \\
\hline No & $85.33(128)$ & $12.0(18)$ & $2.67(4)$ & $100(150)$ & \\
\hline \multicolumn{6}{|l|}{ Previous Graft Failure } \\
\hline Yes & - & $100(27)$ & - & $100(27)$ & 0.000 \\
\hline No & $69.27(160)$ & $29.0(67)$ & $1.73(4)$ & $100(231)$ & \\
\hline \multicolumn{6}{|l|}{ Vascularization } \\
\hline Yes & $57.28(59)$ & $40.78(42)$ & $1.94(2)$ & $100(103)$ & 0.362 \\
\hline No & $66.2(94)$ & $32.39(46)$ & $1.41(2)$ & $100(142)$ & \\
\hline \multicolumn{6}{|l|}{ Eye Classification } \\
\hline Phakic & $77.13(145)$ & $20.74(39)$ & $2.13(4)$ & $100(188)$ & 0.000 \\
\hline Pseudophakic & $15.38(08)$ & $84.62(44)$ & - & $100(52)$ & \\
\hline Aphakic & $16.67(01)$ & $83.33(05)$ & - & $100(06)$ & \\
\hline \multicolumn{6}{|l|}{ Glaucoma } \\
\hline Yes & $23.08(06)$ & $76.92(20)$ & - & $100(26)$ & 0.000 \\
\hline No & $67.12(147)$ & $31.05(68)$ & $1.83(4)$ & $100(219)$ & \\
\hline \multicolumn{6}{|c|}{ Transoperative Complications } \\
\hline Yes & $54.55(12)$ & $40.9(09)$ & $4.55(1)$ & $100(22)$ & 0.449 \\
\hline No & $63.01(138)$ & $35.62(78)$ & $1.37(3)$ & $100(219)$ & \\
\hline
\end{tabular}

* Chi-square test. The chi-square test was applied for inferential statistical analysis only for the most frequent types of corneal disorders (stromal and endothelial).

\section{Discussion}

The clinical profile description of cornea transplant patients presented in this study points to a discrete predominance of males and corneal disorders distributed throughout all age groups, which corroborates the results found in individuals submitted to cornea transplants in other countries such as Canada, Iran and Italy ${ }^{(11-13)}$.

The main indicator for cornea transplant in the hospital was keratoconus. Other disorders such as interstitial keratitis and bullous keratopathy were also prevalent in the results. The main indications for cornea transplant may vary according to the time period studied, the data collection location, age group of the population, as well as environmental and cultural factors as verified in studies in Canada, Italy and New Zealand(4,11,13-15). These studies presented Fuchs's dystrophy (Canada) and keratoconus (Italy and New Zealand) as the main indicators for cornea transplant.

Therefore, due to this variability in the clinical profile of indicators for cornea transplantation, determining indicative diseases for performing this procedure according to time and space is essential in order to obtain adequate management of the patients, as well as restoring their quality of $\operatorname{life}^{(4)}$. 
The present study sought to identify the main indicator for cornea transplant in the state of Rio Grande do Norte in order to increase knowledge about the topic, and from this contribute to managing these patients throughout the whole transplantation process, providing specific care for patients undergoing transplantation. Care focused on the intrinsic and extrinsic conditions of each ocular diagnosis may contribute to the graft's final result.

Temporal distribution is observed by a significant increase in the number of transplants over time, with emphasis on the year 2014, where a representative percentage of $44.18 \%$ of the transplants performed at HUOL was observed throughout the studied period.

The growing number of keratoplasties may be associated with increased availability of corneas for transplants by increasing people's awareness regarding current treatment perspectives, the prevention of ocular diseases, early diagnosis, educational campaigns, new surgical techniques and better prognostics.

Although the number of cornea transplants in the state of Rio Grande do Norte showed a substantial increase, the geographical distribution of cases (Figure 1) suggests heterogeneity in relation to the four mesoregions of the state, with a higher prevalence in the Eastern Potiguar mesoregion (more precisely in the state capital and is the metropolitan region). Such an indicator is related to problems such as difficulties in accessing specialized services and consequent impairment for the early diagnosis of cases in which cornea transplant represents the appropriate therapeutic conduct.

The geographical heterogeneity in the performance of cornea transplant represents a diagnosis of a public health problem. Given such results, we should reflect that eye health is not being effectively addressed by the doctrinal principle of regionalization guaranteed by the Unified Health System.

Moreover, we found an expressive number of corneal disorders in a young population with diagnoses of ocular diseases that could be prevented, which if treated early would not require cornea transplant (as is the case with keratitis, bullous keratopathies and leukomas).

The average waiting time for cornea transplant was 172.63 days ( 5 months and 3 weeks) for elective transplants and 9.03 days for urgent cases. In the national context, the waiting time for cornea transplants varies according to each region. In the state of Pernambuco (northeastern Brazil), it was observed that more than half of the patients wait between one to six months on the waiting list ${ }^{(4)}$.

A study conducted in the province of Quebec, Canada, from 2000 to 2011, identified that the waiting time in the period from 2000 to 2008 was 434 days, and from 2009 to 2011 it was 418 days, equivalent to approximately one year and two months. ${ }^{(16)}$ The waiting time for performing cornea transplant involves several factors such as records of family refusals, a decrease in the effective number of donors, and inefficient tracking of potential donors.

Through inferential analysis, the present study found a statistically significant difference between stromal corneal disorders with males and those between 20 and 50 years of age. The relationship established with the age variable may be justified by the main type of stromal disorders presented, such as keratoconus and interstitial keratitis, which are more prevalent in the lower age groups and more frequently affect younger individuals and adults(12-14). However, the association between the type of stromal disorder and males should be considered by future longitudinal studies due to the lack of current studies that report or investigate such a relationship.

Regarding endothelial disorders, an association of these with age over 60 years, cases of prior surgery to transplant, pseudophakic and aphakic eye classification, anterior graft failure and presence of glaucoma were found.

On average, the human cornea has an endothelial cell density of $5,000-6,000$ cells $/ \mathrm{mm}^{2}$ at birth. They decrease to about $2,500-3,000$ cells $/ \mathrm{mm}^{2}$ in adulthood, with a mean cell loss of $0.6 \%$ per year and do not have regenerative cellular properties. Therefore, once corneal endothelial cells are lost, they cannot be physiologically replaced.(17) Thus, the aging process consists of a predictive factor for diseases that aggravate the corneal endothelium, which justifies the association of these types of disorders in individuals over 60 years of age in the present study.

Previous history of ocular surgeries that damage the posterior layers of corneal tissue can result in endothelial damage, and consequently loss of corneal transparency; a situation that in some cases requires transplant as treatment. Cataract surgery, for example, for the purpose of removing or replacing the lens with intraocular lenses, is a type of surgery that often results in aggression to the corneal endothelium, and may trigger a clinical condition of pseudophakic bullous keratopathy, one of the main indicators for cornea transplantation ${ }^{(13,17)}$.

Like any surgical procedure, cornea transplants are also subject to failure, which may occur due to a number of factors. These factors may either result from adverse effects of the underlying disease, or from endothelial failure, immune rejection or the type of surgical technique(18-21).

The main surgical technique used in the studied hospital was penetrating keratoplasty $(92.68 \%)$, which 
consists of replacing all corneal layers. It has been the dominant procedure for over half a century, successfully addressing most of the causes of corneal blindness. However, this technique poses greater graft failure risks since it replaces the recipient's corneal endothelium. As an alternative, new lamellar transplantation techniques have emerged that selectively replace only the affected corneal layers while reducing the risk of endothelial rejection ${ }^{(19-21)}$.

Because the function of endothelial cells is to ensure clarity and transparency of the cornea, loss of endothelial cells is an important condition that should be evaluated after keratoplasty. Examining the reduction of endothelial density allows for evaluating the quality of the corneal endothelium. Studies show that the loss of endothelial cell density is greater(21-23) in surgical techniques that do not preserve the corneal endothelium, as well as in ocular diseases that compromise the corneal endothelium. These data may justify the results found in the present study that relate cases of graft failure of previous transplants to corneal endothelial disorders. Thus, it has been observed that recurrent transplantation is commonly associated with endothelial disorders that affect the cornea after the first transplant. Investing in surgical techniques that minimize damage to the corneal endothelium may result in better prognosis.

In cases in with no endothelium impairment, anterior lamellar keratoplasty represents a promising therapeutic approach with longer survival. This has been one of the discoveries that is driving a transition from penetrating keratoplasty to lamellar keratoplasty, a technique in which endothelial cells can be retained and little affected ${ }^{(22-23)}$.

Glaucoma is also associated with corneal endothelial disorders, and is a serious multifactorial disease characterized by elevated intraocular pressure, as well as retinal and optic nerve cell death. Chronic elevation of intraocular pressure compromises the corneal endothelium, leading to accelerated endothelial cell losses, and limits the prognosis and represents a risk factor for graft failure ${ }^{(20,22,24)}$ in cases where cornea transplant has been performed.

Studies have reported that increased intraocular pressure is another risk factor for endothelial cell loss after keratoplasty, especially penetrating keratoplasty $(20,22,24)$. Glaucoma behaves as a predictor for corneal tissue impairment, both pre and post-transplant. Investigating, monitoring and controlling this comorbidity must be performed throughout the transplant process, from its identification in the preoperative period, to its maintenance in the postoperative period by all professionals involved in patient care.

The nursing consultation is an important tool for investigating and implementing care that guarantees the patient ideal conditions for transplant and graft maintenance in the immediate and mediate postoperative period $^{(25)}$. However, in the state of Rio Grande do Norte, follow-up of these patients between the preoperative and the postoperative periods is performed by the medical ophthalmologic team, while the nursing team acts in the transoperative care.

Nursing care should include all surgical periods from patient indication to the transplant until their discharge. Nursing consultations can be used to identify risk factors, existing comorbidities, therapeutic adherence, appropriate use of medications, performance of physical eye examinations, and control of modifiable risk factors, thus ensuring improvement in the quality and transparency of the graft for a longer time.

We must point out that because this study data was collected from secondary sources, this study (as well as other studies that also use this technique), presents some biases that may be limiting factors, such as loss of information, and weaknesses in records and information systems.

\section{Conclusion}

Based on the clinical profile of cornea transplant, we found that factors such as age, previous corneal graft failure, glaucoma, and cases of surgeries prior to cornea transplant (especially cataract surgery) are related to involvement of the corneal endothelium and consequently an appearance of endothelial-type corneal disorders. Therefore, these disorders may interfere with prognosis in cases where cornea transplant is indicated as a therapeutic condition.

The main indicator for cornea transplant in the studied hospital was keratoconus, and the main surgical technique was penetrating keratoplasty.

The waiting time found was approximately five months and three weeks for elective cornea transplant, and nine days for urgent cases. This represents an important indicator that may be related to the consequences of therapeutic delay, complications in the patients and the probabilities of care and cure.

Understanding the clinical profile of cornea transplant patients may enable identification of risk groups for prevention and care implementation purposes that result in improved prognoses.

\section{References}

1. Sundaram N. A close look at cornea. Indian J Ophthalmol. [Internet], 2014 [Cited Oct 25 2016]; 62 (4): 381-2. Available from: https://www.ncbi.nlm.nih. gov/pmc/articles/PMC4064207/ 
2. Albert DM, Gamm DM. Cornea. Britannica Academic. [Internet], 2016 [Cited Oct 27 2016]. Available from: http://academic-eb-britannica.ez18. periodicos.capes. gov.br/levels/collegiate/article/26332

3. Chaurasia SS, Lim RR, Lakshminarayanan R, Mohan RR. Nanomedicine Approaches for Corneal Diseases. J Funct Biomater. [Internet] 2015 [Cited Oct 24 2016]; 6(2):277-98. Available from: https://www.ncbi.nlm.nih. gov/pmc/articles/PMC4493512/

4. Almeida HG, Souza ACD. Epidemiological profile of patients waiting for penetrating keratoplasty in state of Pernambuco - Brazil. Rev Bras Oftalmol. [Internet] 2014 [Cited Jul 25 2015]; 73(1): 28-32. Available from: http://www.scielo.br/scielo.php?script=sci_arttext\&pid $=$ S0034-72802014000100028

5. Xu SC, Chow J, Liu J, Li L, Maslin JS, Chadha N, et al. Risk factors for visual impairment associated with corneal diseases in southern China. Clin Ophthalmol. [Internet] 2016 [Cited Oct 24 2016]; 10: 777-82. Available from: https://www.ncbi.nlm.nih.gov/pmc/ articles/PMC4859424/

6. Gain P, Jullienne R, He Z, Aldossary M, Acquart S, Cognasse $F$, et al. Global survey of corneal transplantation and eye banking. JAMA Ophthalmol. [Internet] 2016 [Cited Oct 25 2016]; 134 (2): 167-73. Available from: https://www.ncbi.nlm.nih.gov/pubmed/26633035

7. Ple-Plakon PA, Shtein RM. Trends in corneal transplantation: indications and techniques. Curr Opin Ophthalmol. [Internet] 2014 [Cited Oct 24 2016]; 25(4):300-5. Available from: https://www.ncbi.nlm.nih. gov/pubmed/24865170

8. Pineda, R. Corneal transplantation in the developing world lessons learned and meeting the challenge. Cornea [Internet] 2015 [Cited Oct 22 2016]; 34(10):S35-S40. Available from: https://www.ncbi.nlm.nih.gov/pubmed/26266438

9. World Health Organization (WHO). Visual impairment and blindness. 2014. [Cited Oct 23t 2016]. Available at:http://www.who.int/mediacentre/factsheets/fs282/en/ 10. World Health Organization. Priority eye diseases. 2014. [Cited Oct 23 2016]. Available at:http://www. who.int/blindness/causes/priority/en/index8.html

11. Tan JC, Holland SP, Dubord PJ, Moloney G, McCarthy $M$, Yeung SN. Evolving indications for and trends in keratoplasty in British Columbia, Canada, from 2002 to 2011: a 10-year review. Cornea. [Internet] 2014 [Cited Jul 13 2015]; 33 (3): 252-6. Available from: http:// www.ncbi.nlm.nih.gov/pubmed/24457452

12. Kanavi MR, Javadi MA, Motevasseli T, Chamani T, Kanavi MR, Kheiri B, et al. Trends in indications and techniques of corneal transplantation in Iran from 2006 to 2013; an 8-year review. J Ophthalmic Vis Res. [Internet] 2016 [Cited Oct 26 2016]; 11(2):146-
52. Available from: https://www.ncbi.nlm.nih.gov/ pubmed/27413493

13. Frigo AC, Fasolo A, Capuzzo C, Fornea M, Bellucci $R$, Busin $M$, et al. Corneal Transplantation Activity Over 7 Years: Changing Trends for Indications, Patient Demographics and Surgical Techniques From the Corneal Transplant Epidemiological Study (CORTES). Transp Proceedings. [Internet] 2015 [Cited July 20 2015]; 47(2): 528-35. Available from: http://www.ncbi. nlm.nih.gov/pubmed/25769602

14. Kim BZ, Meyer JJ, Brookes NH, Moffatt SL, Twohill HC, Pendergrast DG, et al. New Zeland trends in corneal transplantation over the 25 years 19912015. Br J Ophthalmol. [Internet] 2016 [Cited Oct 25 2016]. Available from: https://www.ncbi.nlm.nih.gov/ pubmed/27635063

15. Gogia V, Gupta S, Titiyal JS, Panda A, Pandey RM, Tandon R. A preliminary descriptive analysis of Corneal Transplant Registry of National Eye Bank in India. Cont Lens Ant Eye. [Internet] 2014 [Cited July 15 2015]; 37(2): 111-5. Available from: http://www.ncbi.nlm.nih. gov/pubmed/24064181

16. Robert M, Choronzey ML, Lapointe J, Meunier LG, Dagher $\mathrm{MH}$, Germain M, et al. Evolution of Corneal Transplantation in the Province of Quebec From 2000 to 2011. Cornea. [Internet] 2015[Cited Aug 5 2016]; 34 (8): 880-7. Available from: http://www.ncbi.nlm.nih. gov/pubmed/26057325

17. Guell JL, Husseiny MAE, Manero F, Gris O, Elies D. Historical Review and Update of Surgical Treatment for Corneal Endothelial Diseases. Ophthalmol Ther. [Internet] 2014 [Cited July 27 2015]; 3(2): 1-15. Available from: http://www.ncbi.nlm.nih.gov/pubmed/25134494

18. Emami-Naeini $P$, Dohlman $\mathrm{TH}$, Omoto $M$, Hattori $T$, Chen $Y$, Lee HS, et al. Soluble vascular endothelial growth factor receptor-3 suppresses allosensitization and promotes corneal allograft survival. Graefes Arch Clin Exp Ophthalmol. [Internet] 2014 [Cited Oct 28 2016]; 252(11):1755-62. Available from: https://www. ncbi.nlm.nih.gov/pubmed/25091513

19. Mitry D, Bhogal M, Patel AK, Lee BS, Chai SM, Price $M O$, et al. Descemet stripping automated endotelial keratoplasty after failed penetrating keratoplasty: survival, rejection risk, and visual outcome. JAMA Ophthalmol. [Internet], 2014 [Cited Oct 28 2016]; 132(6):742-9. Available from: https://www.ncbi.nlm. nih.gov/pubmed/24763830

20. Iverson SM, Spierer O, Papachristou GC, Feuer WJ, Shi W, Greenfield DS, et al. Comparison of primary graft survival following penetrating keratoplasty and Descemet's stripping endothelial keratoplasty in eyes with prior trabeculectomy. $\mathrm{Br}$ J Ophthalmol. [Internet] 2015 [Cited Oct 29 2016]; 99:1477-82. Available 
from: http://bjo.bmj.com/content/early/2015/04/30/ bjophthalmol-2014-306547.

21. Borderie VM, Georgeon C, Bouheraoua N. Influence of surgical technique on graft and endothelial survival in endothelial keratoplasty. J Fr Ophtalmol. [Internet], 2014 [Cited Oct 30 2016]; 37(9): 675-81. Available from: https://www.ncbi.nlm.nih.gov/pubmed/25287818

22. Anil K, Arif K, Esin SS, Sibel A, Ekrem K, Yusuf O. Corneal endothelium after deep anterior lamellar keratoplasty and penetrating keratoplasty for keratoconus: A four-year comparative study. Indian $\mathrm{J}$. Ophthalmol. [Internet], 2012 [Cited July 29 2015]; 60 (1): 35-40. Available from: http://www.ncbi.nlm.nih. gov/pubmed/22218243

23. Sugar A. The importance of corneal endothelial cell survival after endothelial keratoplasty. JAMA Ophthalmol. [Internet], 2015 [Cited Oct 30 2016]; 133(11): 12856. Available from: http://jamanetwork.com/journals/ jamaophthalmology/article-abstract/2436653

24. Suhett WG, Pereira Júnior OCM, Yamamoto LK, Mendes LMP, Cazangi D, Barbosa LV, et al. Clinical evaluation of the association of technique and drug ablation flap of third eyelid for treatment in case of canine glaucoma with corneal ulcer as aggravating - case report. Rev Ciên Vet Saúde Pública. [Internet] 2014 [Cited July 27 2015]; 1(2): 135-140. Available from:periodicos.uem.br/ojs/index.php/RevCiVet/article/ download/19908/pdf_47

25. Hinkle JL, Cheever KH. Brunner \& Suddarth Tratado de Enfermagem medico-cirúrgico. 13 ed. Brasil: Guanabara; 2015. 2396 p. Creative Commons (CC BY).

This license lets others distribute, remix, tweak, and build upon your work, even commercially, as long as they credit you for the original creation. This is the most accommodating of licenses offered. Recommended for maximum dissemination and use of licensed materials. 